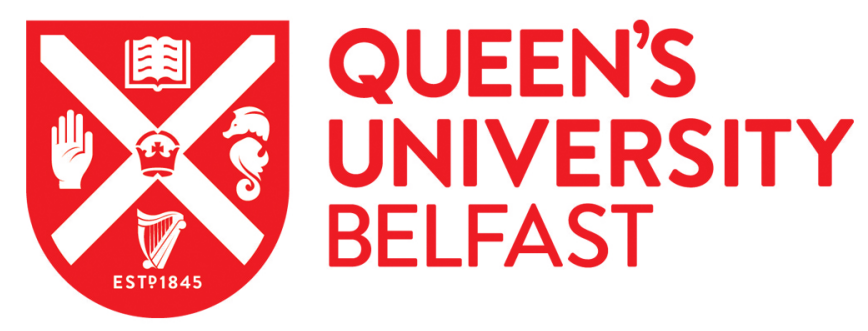

\title{
Examining the experience of undergoing group Cognitive Behavioural Therapy for Obsessive Compulsive Disorder: An Interpretative Phenomenological Analysis
}

Black, P., Hanna, D., Quinn, P., \& Dyer, K. (2018). Examining the experience of undergoing group Cognitive Behavioural Therapy for Obsessive Compulsive Disorder: An Interpretative Phenomenological Analysis. International Journal of Group Psychotherapy, 68(2), 195-203. https://doi.org/10.1080/00207284.2017.1403852

Published in:

International Journal of Group Psychotherapy

Document Version:

Peer reviewed version

Queen's University Belfast - Research Portal:

Link to publication record in Queen's University Belfast Research Portal

Publisher rights

() The American Group Psychotherapy Association, Inc.

This work is made available online in accordance with the publisher's policies. Please refer to any applicable terms of use of the publisher.

\section{General rights}

Copyright for the publications made accessible via the Queen's University Belfast Research Portal is retained by the author(s) and / or other copyright owners and it is a condition of accessing these publications that users recognise and abide by the legal requirements associated with these rights.

Take down policy

The Research Portal is Queen's institutional repository that provides access to Queen's research output. Every effort has been made to ensure that content in the Research Portal does not infringe any person's rights, or applicable UK laws. If you discover content in the

Research Portal that you believe breaches copyright or violates any law, please contact openaccess@qub.ac.uk. 
Title: Examining the experience of undergoing group Cognitive Behavioural Therapy for Obsessive Compulsive Disorder: An Interpretative Phenomenological Analysis.

Authors: $\quad$ Peter Black ${ }^{1}$, Donncha Hanna*1, Paul Quinn² \& Kevin Dyer ${ }^{1,3}$.

*Corresponding authors: donncha.hanna@qub.ac.uk \& k.dyer@qub.ac.uk

${ }^{1}$ School of Psychology, Queens University of Belfast, N.Ireland.

${ }^{2}$ International Institute for Cognitive Therapy, Belfast, N.Ireland.

${ }^{3}$ Psychological Therapies Service, NHSCT, Antrim, Northern Ireland

Running Head: The experience of group CBT for OCD: An IPA study

Word count: 2654 (including references and tables)

Keywords: Obsessive-compulsive disorder; cognitive-behavioural therapy; group therapy; Interpretative Phenomenological Analysis; group cohesion. 


\begin{abstract}
This study used Interpretative Phenomenological Analysis to explore the lived experiences of five individuals diagnosed with OCD who underwent a group Cognitive Behavioural Therapy (CBT) intervention programme to address their symptoms. Two master themes were identified: experiences and processes of change and reflections on change. For all participants, the degree of group cohesion or connectedness they established with group members emerged as highly important in facilitating therapeutic progress. A number of technical elements of CBT were also notable therapeutic factors including questioning/rationalising maladaptive interpretations about intrusions. However, the commonality of non-specific group processes as key features for subsequent therapeutic change prompts the need for further research in dynamics within CBT group interventions for OCD.
\end{abstract}

Examining the experience of undergoing group Cognitive Behavioural Therapy for Obsessive Compulsive Disorder: An Interpretative Phenomenological Analysis

Cognitive Behavioural Therapy (CBT) is recommended as the primary treatment of choice for Obsessive-Compulsive Disorder (OCD; National Institute of Clinical Excellence, 2006). CBT intervention studies have shown that group OCD programmes are largely equivalent to traditional individual therapy in reducing symptomatology (Sunde et al., 2017; Whittal, Robichaud, Thordarson, \& McLean, 2008). Relatively less research attention has been given to understanding how intra-group dynamics influence such protocolised OCD group interventions.

Mechanisms of change within group therapy can derive not only from evidence-based CBT components, but also from more non-specific processes occurring within the group 
dynamic (Harper Romeo, Meyer, Johnson, \& Penn, 2014). For example, studies have identified Exposure and Response Prevention (ERP) as a key therapeutic element for an effective OCD group (McLean et al., 2001). However, as yet, no studies have explored how important underlying group conditions are for successful OCD group therapy. Yalom (1975) was the first and most influential researcher to investigate curative or therapeutic factors in group psychotherapy. Of these, group cohesiveness has been regarded as a prominent metatherapeutic factor, whereby the presence of cohesiveness within the group dynamic increases the likelihood that other conducive factors (e.g., interpersonal learning) will develop. Consequently, the absence of cohesiveness could represent a significant barrier to CBT group therapy for OCD.

The primary aim of this study was to explore the lived experience of service-users' undergoing a $\mathrm{CBT}$ OCD group in order to understand potential influential therapeutic factors within this treatment modality. Interpretative Phenomenological Analysis (IPA: Smith, Flowers and Larkin, 2009) was employed as this methodology is useful in process-oriented research and for gaining insight into qualitative characteristics of change mechanisms (Wilson \& Chambless, 2005).

\section{Method}

\section{Participants}

Participants were recruited via a purposive sampling from two group CBT programmes. Inclusion criteria were 1) a primary diagnosis of OCD and 2) to have attended at least four group sessions. Exclusion criteria were 1) active abuse of drugs/alcohol; 2) active engagement in self-harm behaviours; and 3) currently experiencing suicidal ideation/intent. Nineteen group attendees met these criteria. Five service-users anonymised as Mike, Keith, Tim, Sarah, and Rachel consented to participate in the study -4 completed therapy and 1 
(Keith) withdrew midway through therapy due to a bereavement. The average age of the five participants ( 3 male and 2 female) was 45 years. Three of the participants were on various combinations of antidepressant and anxiolytic medications.

\section{Group CBT programme}

The CBT group consisted of 15 sessions split into five phases entitled "Understanding OCD”, "Exposure and Response Prevention 1", "Exposure and Response Prevention 2", "Understanding the Cognitive Impact of OCD" and "Completion of the Group CBT for OCD”. Sessions $1-3$ focussed on psychoeducation for the overall group. Sessions $4-15$ involved subgroup tasks and the implementation of CBT techniques. Weekly homeworks were related to session content (e.g., drafting exposure hierarchies). Telephone contact and periodic home visits were also between-session features of the programme.

\section{Data collection and analysis}

Interviews were audio-recorded/transcribed for IPA by PB and credibility checks were performed with DH. The interview structure and five-stage analysis process was guided by recommended IPA procedures (see Smith et al., 2009). The interview followed a semistructured schedule where participants were asked questions in several areas including descriptive content (e.g., "Describe to me what the group programme involved") and evaluating personal meaning (e.g., "Reflecting on your experience of the group, overall what did it mean to you to be involved in the group?").

\section{Findings}

The two master themes along with their associated sub-ordinate themes identified during the analysis are presented in Table 1. 
Table 1. Table of master and sub-ordinate themes

\begin{tabular}{|l|l|}
\hline Master themes & Sub-ordinate themes \\
\hline \multirow{3}{*}{ Experiences and processes of change } & Initial impressions and reactions \\
\cline { 2 - 2 } & Sub-groups as a catalyst for change \\
\cline { 2 - 2 } & A connectedness in not feeling the only one \\
\cline { 2 - 2 } & Impetus to achieve \\
\hline Reflections on change & Current functioning \\
\cline { 2 - 2 } & What was taken away from the group \\
\hline
\end{tabular}

\section{Master theme 1: Experiences and Processes of Change}

Four key experiences and processes emerged across participants as being instrumental in affecting change in the management of their OCD.

Initial impressions and reactions. All participants depicted the experience of first meeting the other members in their own way. Tim spoke of the group dynamic helping to "bring the OCD out of you more or less" through the mere act of talking and how "once you were talking to people, it helped you right away". Sarah portrayed a difficult first few sessions in the group due to pessimism about whether the group would help her with her OCD symptoms. She perceived there to have been an "awkward" atmosphere within the group in the early stages. A change towards a more settled group atmosphere was noticed however once a number of volunteers had come forward to demonstrate exposure exercises.

“...people sort of softened to each other you'd sort of seen that cause you'd see somebody who was...put in a situation that makes them so horribly anxious and you sort of, you really felt for them...So everybody, I think we all settled into the group a little bit after that...”

(Sarah)

Sub-groups as a catalyst of change. Splitting into smaller sub-groups led to closer relations, greater empathy with fellow group members, and an appreciation of the commonalities 
underlying their experiences of OCD, which were particularly meaningful in instigating change within themselves. Mike commented on how splitting into the smaller groups helped with developing "bonds" with the other members and perceived that this process did not negatively affect or fragment the cohesiveness of the group as a whole. Sarah also described how the subgroups, through the sharing of advice between members, facilitated a shift at around week 4 or 5 from completing the exposure exercises simply to please the facilitators to doing the exercises for her own recovery and, ultimately, to become her own therapist.

"I suppose that was just making you think more like a therapist and be your own therapist or be your group member's therapist...it was a good exercise in breaking the ties with [the therapists] and be like "Right, you have to do it yourself". " (Sarah)

A connectedness in not feeling the only one. Participants also reported the influence that spread amongst group members of not feeling that you're the only one with OCD once commonalities between group members' experiences had been recognised. Tim spoke of firstly the importance of hearing about how OCD affected others and the help he found in feeling understood. He also discussed how the group served as a helpful forum to reflect on whether the strategies others were trying might help him to overcome his OCD.

"Everybody tried to help each other and what they were saying you were listening to it...Ah I wonder if I tried that, would that help me? You know, so...everybody was listening to each other to try to pick up something different from somebody else....It was all feeding round, you know? We all spoke and we were all listening and interested in what they said.” (Tim)

Impetus to achieve. An impetus to achieve one's exposure goals and an added desire to manage their OCD developed once a level of connectedness had been established between members. Having previously engaged in private individual therapy, Rachel talked about 
benefitting from observing the strategies employed by others as they gave her motivation and insight into managing her own OCD symptoms.

"I think it [observing others] puts it in perspective...If the two people on my left and on my right are experiencing the same thing and I can then see how they've tackled it, I sort of nearly take it on myself and filter it through.” (Rachel)

However, Keith perceived that there was also an overarching desire to want to please therapists in his group but felt that this aspect could mask of the truth regarding peoples' actual status in addressing their OCD.

“...people don't always tell the truth, whether they're embarrassed, whether they want to please. It's human nature to want to please...You know so, you're hardly going to turn round and say to [the therapist] in front of ten, nine other people 'That didn't really work for me [therapist]. I only done that cause I wanted to please you'”. (Keith)

\section{Master theme 2: Reflections on Change}

Much of the interview content contained retrospective reflections on what each participant had taken away from the group experience and their subsequent management of their OCD.

Current functioning. With the exception of Keith, the other four participants spoke at length of the significant gains they had made as a result of the group. Despite these improvements, all participants spoke of having residual obsessive-compulsive symptoms that they were continuing to work on. Mike talked about how progress for him was incremental, having gradually made small improvements over the year since the group had finished. He was continuing to focus on certain areas of his OCD and spoke of aspirations to be free of particular compulsions first before moving on to others. 
"So what I've been doing since the group is I've been trying to work on, you know. Now I would have liked to have been able to say "Look right, I've worked on that area ahmm and I'm free of that now, I've moved on to something else..."...It hasn't worked out just...quite like that in a sense.” (Mike)

Rachel emphasised how much she had improved and gained from the group and regarded most of her symptoms to either be "gone" or in the process of "going". However, there was also acceptance that her OCD may never be "fully gone".

What was taken away from the group. Dealing with symptoms one at a time and an incremental speed of change was something that participants spoke of taking from the group. Mike reflected on how the course had given him a structured, paced way of dealing with his OCD. Sarah appeared to have taken away a different method of managing her obsessive thoughts, from previous attempts at distraction and avoidance of intrusions to willingness in accepting their occurrence.

“...there probably will be thoughts that are going to jump into my head and they're going to worry me, but now it's like "Well, they're just thoughts"...I quite like that idea that this is just a thought. It doesn't really have to mean anything. Your life's going to keep on moving in whatever direction it's moving despite it. It as if it's separating the thoughts from me and my actions.” (Sarah)

\section{Discussion}

The present study revealed two master themes relevant to the lived experience of undergoing a CBT OCD group, namely 1) elements and processes of change, and 2) reflections on change. Across both master themes, several key components were identified as important for a successful therapeutic group. In elements and processes of change, 
establishing a degree of connectedness with fellow group members was a central factor in facilitating therapeutic progress, suggesting Yalom's (1975) concept of group cohesiveness was an underlying foundation for change. Dividing into subgroups was also seen as instrumental in developing more "in-depth" connections or "bonds" with fellow members. A number of technical elements of CBT also emerged as notable therapeutic factors. In "what was taken away from the group", Sarah asserted that her interpretations of obsessive intrusions altered over the course of the group. Her move from using distraction/avoidance as a means of coping with distressing thoughts to questioning and rationalising maladaptive interpretations about her intrusions could possibly be evidence of change at the metacognitive level. This supports the effectiveness of targeting these cognitive aspects of OCD (Fisher \& Wells, 2008; Storchheim \& O’Mahony, 2006).

The findings of this study offer clinical implications for evidence-based OCD group treatments. The reflections of participants underline the need for group therapy programmes to strike a balance between evidence-based group tasks (e.g. ERP exercises) and providing space for group cohesion and the sharing of personal narratives. Group therapy should take into account the importance of hearing about the person behind the OCD and not focus purely on symptom reduction, as the former serves as a central mechanism of change in its own right. Degree of group cohesion and therapeutic change across Yalom's curative factors could be measured as outcomes in therapy using the Group Questionnaire (Krogel, 2009) and Therapeutic Factors Inventory (MacNair-Semands, Ogrodniczuk \& Joyce, 2010) respectively.

Despite the utility of the IPA approach, the small sample size and qualitative methodology limits the generalisability of study findings. Larger scale studies could further examine the processes and critical elements of effective CBT group programmes. Such 
interventions for OCD could be tailored to support therapists in becoming better attuned to the processes of group cohesion and its role in group therapy delivery.

In conclusion, the present IPA study revealed that participants with OCD placed a strong emphasis on the therapeutic importance of developing connectedness with fellow group members. This factor was interpreted as a necessary condition or pre-condition for clinical change and was also facilitated by smaller sub-group exercises. This study highlights that, in tandem with the necessary adherence to ERP procedures in the CBT treatment of OCD, clinicians should also focus on fostering group cohesion and understanding the group dynamics at play within therapeutic settings.

\section{$\underline{\text { References }}$}

Fisher P. L., Wells, A. (2008). Metacognitive therapy for obsessive-compulsive disorder: a case series. Journal of Behavior Therapy and Experimental Psychiatry 39(2):117-32.

Harper Romeo, K., Meyer, P. S., Johnson, D., Penn, D. L. (2014). An investigation of the relationship between therapist characteristics and alliance in group therapy for individuals with treatmentresistant auditory hallucinations. Journal of Mental Health, 23, 166-170.

Krogel, J. (2009). The group questionnaire: A new measure of the group relationship. Provo, UT: Brigham Young University.

MacNair-Semands, R. R., Ogodniczuk, J. S. \& Joyce, A. S. (2010). Structure and initial validation of a short form of the Therapeutic Factors Inventory. International Journal of Group Psychotherapy, 60, 245-281. 
McLean, P. D., Whittal, M. L., Thordarson, D. S., Taylor, S., Sochting, I., Koch, W. J., Paterson, R., \& Anderson, K. W. (2001). Cognitive versus Behaviour Therapy in the Group Treatment of Obsessive-Compulsive Disorder. Journal of Consulting and Clinical Psychology, 69 (2), 205214.

National Institute for Clinical Excellence (NICE) (2006). Obsessive compulsive disorder: full guidelines. http://www.nice.org.uk/guidance/CG31/guidance/pdf/English

Smith, J.A., Flowers, P., \& Larkin, M. (2009). Interpretative phenomenological analysis: Theory, method, research. London: Sage.

Storchheim, L. F., \& O’Mahony, J. F. (2006). Compulsive behaviours and levels of belief in obsessivecompulsive disorder: A case-series analysis of their interrelationships. Clinical Psychology and Psychotherapy, 13, 64-79.

Sunde, T., Wlaseth, L. T., Himle, J. A., Vogel, P. A., Launes, G., Haaland, V. O., Hoffart, A., Johnson, S. U., Haaland, A. T. (2017). A long-term follow-up of group behavioral therapy for obsessivecompulsive disorder in a general outpatient clinic in Norway. Journal of Obsessive-Compulsive and Related Disorders, 14, 59 - 64.

Whittal, M. L., Robichaud, M., Thordarson, D. S., \& McLean, P. D. (2008). Group and individual treatment of obsessive-compulsive disorder using cognitive therapy and exposure plus response prevention: A 2-year follow-up of two randomized trials. Journal of Consulting and Clinical Psychology, 76 (6), 1003-1014. 
Wilson, K. A., \& Chambless, D. L. (2005). Cognitive therapy for obsessive-compulsive disorder. Behaviour Research and Therapy, 43, 1645-1654.

Yalom, I.D., The Theory and Practice of Group Psychotherapy. New York: Second edition, Basic Books, 1975. 